AGH DRILLING, OIL, GAS • Vol. 34 • No. $2 \cdot 2017$

http://dx.doi.org/10.7494/drill.2017.34.2.639

Theodore Yao*, Andrew Wojtanowicz**

\title{
CRITERIA AND RISK OF INTEGRITY LOSS FOR WELLS WITH SUSTAINED CASING PRESSURE***
}

\section{INTRODUCTION}

Sustained casing pressure (SCP) is pressure observed in casing annulus that returns after bleed-down and is not the result of thermal affects. Accordingly, occurrence of sustained casing pressure suggests that one or more integrity components within a well have been compromised. The current policy framework for the evaluation of sustained casing pressure in the Outer Continental Shelf (OCS) may not adequately consider all potential safety and environmental risks of the problem. Sustained casing pressure problem is large - affecting 8122 wells and 11498 casing string in the OCS. Reportedly, over $50 \%$ of SCP cases occured in the A annulus, with the remainder of cases observed in casing-casing annuli [6]. Some SCP cases have resulted in toppled facilities and environmental discharge $[6,9]$.

Regulation of sustained casing pressure and casing pressure in offshore oil and gas wells in federal waters is managed by the Bureau of Safety and Environmental Enforcement (BSEE). The regulatory code governing casing pressure and executed by BSEE is 30 CFR 250.519 through 30 CFR 250.530. By incorporation, API Recommended Practice 90, Annular Casing Pressure Management for Offshore Wells, First Edition, 2006 (API RP 90), is the standard which oil and gas operators shall follow, unless a conflict exists between API RP 90 and the CFRs, in which case the CFRs takes priority.

* US Department of Energy

** Louisiana State University

*** This article is written in the author's personal capacity, and does not necessarily represent the viewpoints or perspectives of the Department of Energy or the Federal Government 
For fixed platform wells, annuli must be monitored monthly. For annular pressures that exceed 100 psig, operators must notify BSEE and perform diagnostic testing. If the pressure is considered to be 'low risk', BSEE will permit the well to operate with sustained casing pressure.

The evaluation procedure of sustained casing pressure by BSEE on fixed platform shown in Figure 1 - involves two criteria.

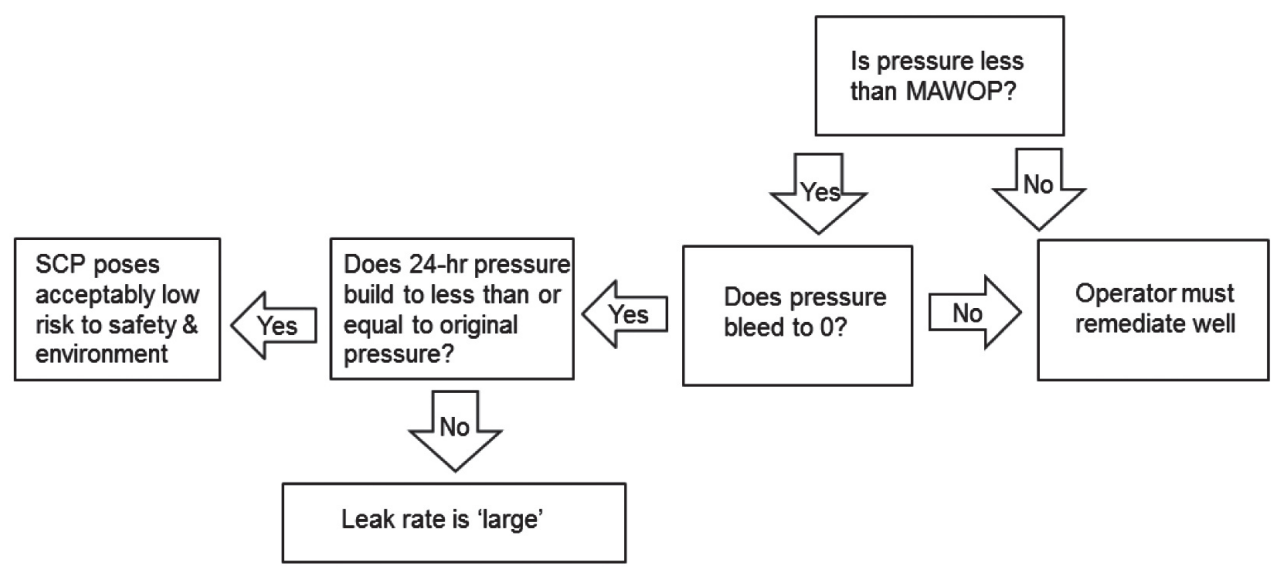

Fig. 1. BSEE procedure for regulatory evaluation of sustained casing pressure in OCS

The first criterion defines the maximum annular pressure limit called maximum allowable wellhead operating pressure (MAWOP). MAWOP is calculated as the lesser of: $50 \%$ of burst for the casing string in question, $75 \%$ of collapse of the inner casing string, $80 \%$ of burst of the next outer string; or if there is no outer string $30 \%$ of burst for the casing string in question, $75 \%$ of collapse of the inner casing string. To be considered to be of sufficiently low risk, the observed pressure at the wellhead must remain below MAWOP.

The second criterion attempts to ascertain whether or not barriers to flow are adequate i.e. there are sufficient barriers to prevent the flow of hydrocarbons into the environment in the event of a toppled facility, for example. Per API RP 90: "SCP that will bleed to zero psig presents an acceptable risk to personnel, property and the environment, since it indicates that the leak rate is small and the barriers to flow are still effective." The criterion additionally stipulates that pressures following the bleed down needs to be monitor and recorded for 24 hours and again suggests that should annular pressures be equal to or less than original pressure, that there is acceptably low risk.

Recently, the two criteria have been critically examined in technical literature $[10,11]$. The first criterion, which permits pressures to reach MAWOP, has been questioned because of its assumptions that loss of well integrity in an annulus can only occur at 
the wellhead. However, as shown in reported accidents [6, 9], well failure may also occur subsurface, below the wellhead. In their review, Kinik and Wojtanowicz [11] show that the sustained casing pressure built at the wellhead may transmit a pressure sufficient to fracture the casing shoe, resulting in a loss of well integrity.

The second criterion that examines the ability to bleed off annular pressure has been considered as merely qualitative and not supported with studies. Kazemi and Wojtanowicz [10] question the ability to deem a low leak rate and assert barrier intactness based upon those findings. They discuss large number of operational factors that influence the ability to bleed-off annular pressures - such as the valve operation, for example. They also question whether or not a well that was capable of bleeding to zero would remain at zero if the bleeding continues. After evacuation of the "gas chamber" (above the free fluid level) the pressure may not be immediately felt at the wellhead within the same period of time that the bleed down occurs, which can occur in a matter of minutes. This potential delay in transmitting pressure is caused by gas slippage through long column of viscous fluid. The effect was demonstrated with simulations showing that in some cases, after the pressure is bled to zero but the valve remains open the wellhead pressure may increase. These findings indicate a need for further examination of the risk criteria performance and possible improvements.

Objective of this study was to examine the second criterion presently used for analysis of testing wells with sustained casing pressure: ability to bleed-off the wellhead pressure to zero and pressure buildup in 24 hours after the bleed-off. Despite being criticized in general terms, as discussed above, little work has been done to use some metrics and examine quantitatively whether meeting the criterion indicates no environmental risk.

\section{METHOD}

\subsection{Cement barrier integrity assessment}

API RP 90 [4] states that should annular pressures could be bled to zero "barriers to flow are still effective". The first quantitative test this paper proposes, seeks to assess API RP 90's claim by examining whether a well's barrier integrity can be considered intact if annular pressures bleeds off.

Consideration of the treatment of sustained casing pressure elsewhere, such as in the North Sea may be useful. Norwegian regulators, the Petroleum Safety Authority (PSA) of Norway, and their associated safety practices in the North Sea, have been, "considered to be the leader in offshore safety practices" [14]. The Norwegian Oil and Gas Associations Recommended Guidelines for Well Integrity suggest a 4 tiered approach toward casing 
pressure management. The four tiers described in the following table, below (Tab. 1). The principle upon which it is based demands two barriers between the environment and hydrocarbon sources. In any producing well, the wellhead generally serves as one barrier.

Table 1

Recommended guidelines for well integrity*

\begin{tabular}{|l|l|}
\hline \multicolumn{1}{|c|}{ Category } & \multicolumn{1}{c|}{ Principle } \\
\hline Red & $\begin{array}{l}\text { One barrier failure and the other is degraded/not verified, or a leak } \\
\text { to surface }\end{array}$ \\
\hline Orange & $\begin{array}{l}\text { One barrier failure and the other is intact, or a single failure may lead } \\
\text { to leak to surface }\end{array}$ \\
\hline Yellow & One barrier degraded, the other is intact \\
\hline Green & Healthy well - no or minor issue \\
\hline
\end{tabular}

* Modified from Norwegian Oil and Gas Associations - Overview of category principle [12]

The wells falling into the "Orange" and "Red" categories are considered as being non-compliant based on concerns regarding their integrity. The criteria for barrier failure verses degradation is also laid out in those guidelines, i.e. the distinction between the 'orange' category and the 'yellow' category, assuming the wellhead is intact. Borrowing from API Recommended Practice 14J, the industry standard accepted to determine the acceptability of leak rates in downhole safety valves, the Norwegian standards suggest that a leak rate of 15 standard cubic feet per minute $(15 \mathrm{scf} / \mathrm{min})$ is an acceptable leak rate for gas and 0.4 liters per minute $(0.4$ liters/min) for a liquid leak rate. These rates are identical to the threshold values also used by industry in other parts of the world for determining whether a particular barrier is considered failed [3].

Accordingly, the $15 \mathrm{scf} / \mathrm{min}$ standard embraced in industry standards, international regulators, and some oil and gas operators it represents a reasonable, quantifiable standard to assess barrier intactness and by extension whether or not well integrity is effectively maintained.

Similar to the downhole safety valve, the partially- compromised cement in an active well would function like a temporary barrier. Per 30 CFR 250.1715, these annular spaces are required to be pressure tested to verify annular isolation, which could be addressed in the abandonment phase of the life of a well.

\subsection{Environmental risk assessment - emission size}

The second criterion used should establish whether or not a well exhibiting signs of sustained casing pressure presents an unacceptable environmental risk of total discharge. 
Several environmental regulations concerning environmental risk exist as potentials which may be considered for the purpose of this project for the development of a quantitative test to assess environmental risk.

Perhaps most applicable, the EPA has regulations that deem the potential to emit of 6 tons of volatile organic compounds (VOC) per year (tpy) as an unacceptable. While the EPA regulations have been applied specifically for oil and gas storage tanks, the regulatory standards stem from what has been determined to be a legal upper limit for unacceptable environmental risk. Accordingly, it is a fair standard by which the environmental risk from a well exhibiting signs of sustained casing pressure can be assessed i.e. whether or not the compromised cement barrier, in the event of a loss of the wellhead, has a potential to emit 6 tpy of VOC into the environment.

\subsection{Collection of field data}

A collection of data from wells - containing complete datasets from 15 wells with sustained casing pressure in the casing-casing annulus - is used. These wells all are fixed platform wells from the Gulf of Mexico. Each set of data contains a relatively complete set of data, including casing specification, size, the hole diameter, proposed drilling fluid to drill the well, and cement volume used. Additionally, each of these wells contains a set of data for a bleed down test conducted, with 24 hours of its subsequent pressure build-up. For each well, the 24-hour pressure build-up was observed to be no higher than the original pre-bleed off pressure.

An additional set of data is available from the literature. Huerta, Checkai, and Bryant [8] present data from two wells with a relatively complete data set. $\mathrm{Xu}$ and Wojtanowicz [15] also present findings for two wells - Well 23 and Well 24. These 15 wells obtained in addition to the wells from literature offer a total of 19 wells for this study.

\subsection{Analysis of cement barrier integrity loss}

Several models have been proposed seeking to estimate parameters from the recorded pressure bleed down and build-up (BB test) patterns in SCP-affected wells of known construction geometry. Perhaps the most critical of the parameters used to obtain a 'match' for the bleed down/build-up are estimations of gas-source reservoir characteristics and cement permeability. Among the models that have been proposed are those by Rocha-Valadez et al. [13], which attempts to model sustained casing pressure build-up without consideration of migration time through the annular fluids. Another, Huerta, Checkai, and Bryant [8] examined the issue of sustained casing pressure and drew analogy to leak rate in well cements for application for leak rate for carbon capture sequestration. Zhu et al. [16] used the complete BB test model of $\mathrm{Xu}$ and Wojtanowicz [15] that 
couples gas flow in the leaking cement with gas migration in stagnant mud column above the cement top. That model has frequently been cited in literature as one of the first to attempt to determine the gas source properties, conductivity of leaking cement in the annulus, and the effect of fluid column length and rheology. The model is used in this study for integrity assessment of cement barrier.

The Xu model simultaneously examines data recorded from two stages of BB test pressure bleed down and pressure build up. During the bleed down stage, gas is flown from the gas chamber (top of the annulus above the free level of liquid) through a half-inch needle valve by considering partial size of the valve's opening. During the build-up stage, gas is assumed to flow through the cement leak and migrate through the liquid column to charge the gas chamber. The $\mathrm{Xu}$ model solves the inverse problem by finding values of annular system parameters - depth and pressure of the gas source, cement permeability, gas holdup in the fluid, gas chamber size, etc. - by matching the recorded test data. In general, the quality of the match can be assessed graphically and qualified with a rudimentary sensitivity analysis.

Using the annular gas flow parameters from the Xu model's output, a steady-state flow rate across the leaking cement barrier may be determined. This calculated flowrate can then be compared against the $15 \mathrm{scf} / \mathrm{min}$ discussed as the critical threshold for the cement barrier integrity loss.

\subsection{Analysis of total environmental gas discharge}

In this study, the Kinik and Wojtanowicz [11] method is used to find the maximum gas discharge from a well with sustained casing pressure in case of the wellhead failure. The model's software has been developed specifically for the output data from the Xu model considering annular fluids of known density having rheological properties of typical drilling muds [6]. The well annulus is assumes either full of the fluid or fluid free, thus the case of partial unloading of the annular fluid is ignored. The maximum gas discharge is then compared with EPA environmental standard, six tons of VOC/year, described above.

\section{RESULTS AND DISCUSSION}

\subsection{Cement barrier integrity}

Data from two wells, 8 and 9, are used to demonstrate the process for determining cement barrier leak rate. Table 2, including gas flow parameters from matching the BB test results shown in Figure 2. 
Table 2

SCP bleed-down/buildup (BB) test analysis in wells 8 and 9

\begin{tabular}{|c|c|c|c|c|c|c|c|c|c|c|}
\cline { 2 - 11 } \multicolumn{1}{c|}{} & $P_{i}$ & $T_{b d}$ & $P_{24 \mathrm{hr}}$ & $I D$ & $O D$ & $\rho_{m}$ & $L_{c}$ & $L_{f}$ & $k$ & $p_{f}$ \\
\hline WELL 8 & 1375 & 14 & 200 & 7.75 & 10.71 & 12.8 & 4000 & 12774 & 20 & 9878 \\
\hline WELL 9 & 3800 & 2 & 750 & 5.5 & 8.681 & 15.6 & 2205 & 9795 & 18 & 11746 \\
\hline
\end{tabular}

a)

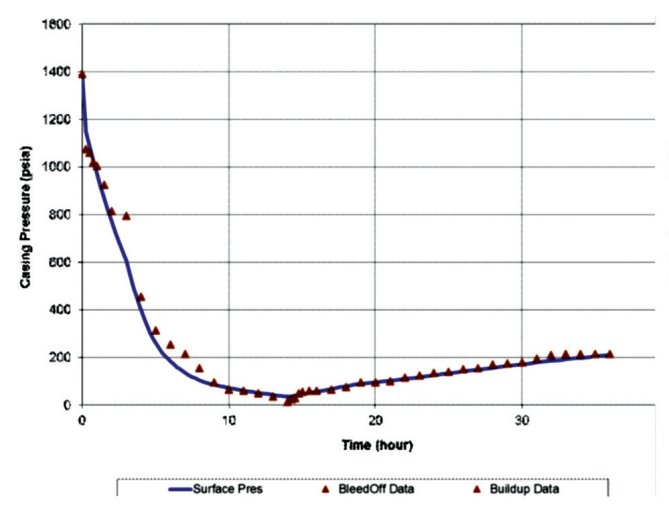

b)

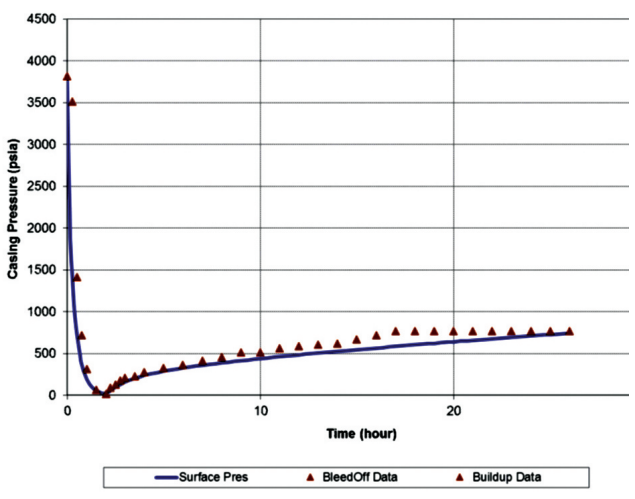

Fig. 2. Matching BB test data for Well 8 (a) and Well 9 (b)

Using the cement leak data from Table 2 and assuming a steady state gas flow, the gas flowrate through the cement barrier is determined for two values of pressure at the top of cement, shown in Table 3. The first more conservative scenario assumes that the annulus above the cement top is filled with seawater having density $8.6 \mathrm{ppg}$. This is an off-shore well scenario of destabilized platform and failed wellhead. The second less conservative scenario examines gas leak rate across the cement barrier assuming that the fluid in the annulus is drilling mud used for drilling the well. As shown in Table 3, for both scenarios, three of the 19 wells (15.8\%) examined would exceed the threshold leak rate of $15 \mathrm{scf} / \mathrm{min}$ that would indicate the cement barrier's integrity failure.

Table 3

Cement barrier integrity data for all wells

\begin{tabular}{|l|c|c|}
\hline \multirow{2}{*}{ Well } & \multicolumn{2}{|c|}{ Leak rate, scf/min } \\
\cline { 2 - 3 } & Seawater & Mud \\
\hline Well 7 & 0.14 & 0.14 \\
\hline Well 8 & 2.82 & 0.93 \\
\hline Well 9 & 5.41 & 2.79 \\
\hline
\end{tabular}


Table 3 cont.

\begin{tabular}{|l|l|l|}
\hline \multirow{2}{*}{ Well } & \multicolumn{2}{|c|}{ Leak rate, scf/min } \\
\cline { 2 - 3 } & Seawater & Mud \\
\hline Well 10 (B annulus) & 0.34 & 0.25 \\
\hline Well 10 (C annulus) & 0.09 & 0.05 \\
\hline Well 12 & 0.01 & 0.01 \\
\hline Well 13 & 6.77 & 5.42 \\
\hline Well 14 & 22.08 & 18.68 \\
\hline Well 19 & 0.03 & 0.03 \\
\hline Well 22 & 38.86 & 31.66 \\
\hline Well 25 & 0.41 & 0.18 \\
\hline Well 33 & 0.08 & 0.03 \\
\hline Well 35 & 0.46 & 0.24 \\
\hline Well 36 & 0.10 & 0.03 \\
\hline Well 38 & 0.01 & 0.01 \\
\hline Well 23 (Xu, 2002) & 0.000095 & 0.000076 \\
\hline Well 24 (Xu, 2002) & 0.000212 & 0.000061 \\
\hline Case 1 (Huerta, 2009) & 27.47 & 16.18 \\
\hline Case 2 (Huerta, 2009) & 0.03 & 0.03 \\
\hline
\end{tabular}

\subsection{Total environmental gas discharge}

The maximum emission rate was determined in scf/D by utilizing the Kinik model with inputs generated by $\mathrm{Xu}$. By assuming the natural gas comprising only volatile organic compounds (VOCs), and using gas specific gravity 0.71 (relative to air), annual mass discharge in tons per year was calculated. Two discharge scenarios are considered: (1) an on-shore well scenario with unloaded annulus (no fluid column above the cement top) and absolute open flow (AOF) gas discharge; and, (2) an off-shore well scenario where the well's annulus is filled with seawater.

As shown in Figures 3 and 4, graphically, the first scenario of AOF gives the gas discharge rate value at the intercept point of the IPR curve with the TPR-AOF plot representing atmospheric pressure at the cement top. For the second scenario, the gas discharge rate marks the intercept of the IPR curve with the horizontal TPR "mud" line representing hydrostatic pressure of the seawater column above the cement top. 
The plots for Well 8 in Figure 3 give 917.8 scf/day (or 6.73 tpy) gas discharge rate from the liquid-free annulus and $458.9 \mathrm{scf} /$ day (or 3.37 tpy) from the annulus filled with seawater.

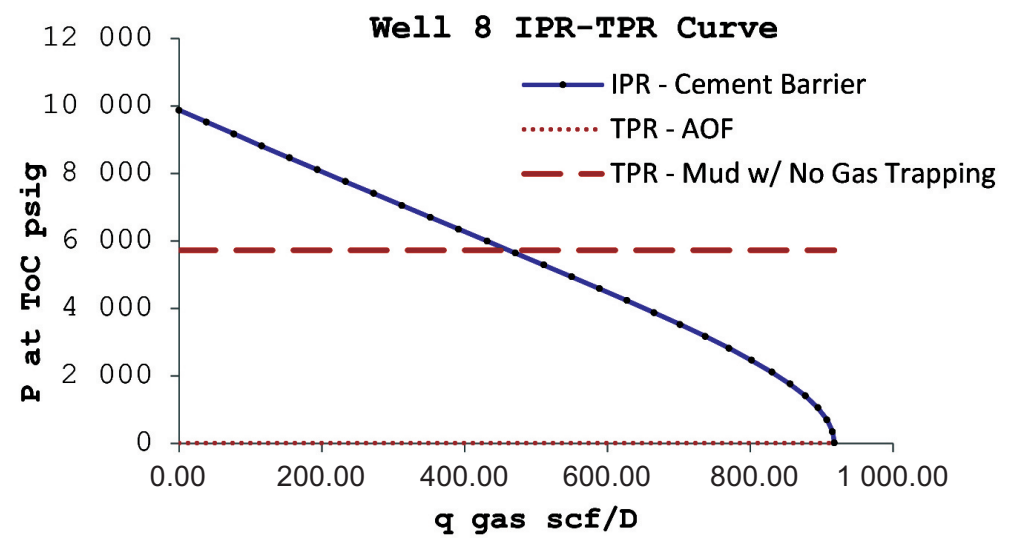

Fig. 3. Gas discharge plots for Well 8

Similarly, the Well 9 plots in Figure 4 indicate gas discharge rate from liquid-free annulus, $725.8 \mathrm{scf} /$ day (or $5.32 \mathrm{tpy}$ ), and the rate $518.45 \mathrm{scf} /$ day (or $3.8 \mathrm{tpy}$ ) for the annulus filled with seawater.

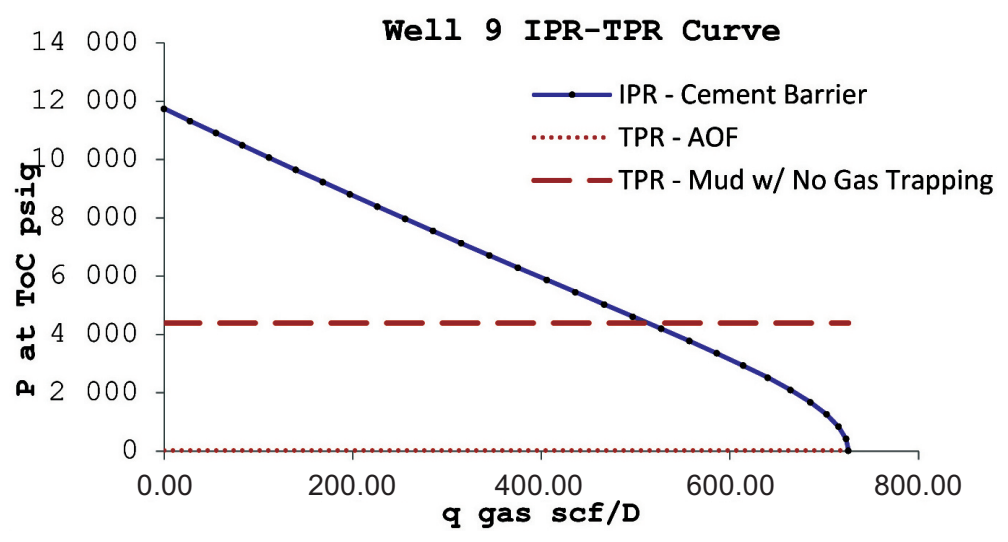

Fig. 4. Gas discharge plots for Well 9

Results for all wells studied are shown in Table 4. For the AOF scenario, five of 19 wells $(26.3 \%)$ would fail the threshold value of 6 tpy. For the offshore scenario (seawater in the annulus), three of 19 wells $(15.8 \%)$ would exceed the threshold of environmental risk. 
Table 4

Gas discharge data for all wells

\begin{tabular}{|l|l|l|}
\hline \multirow{2}{*}{ Well } & \multicolumn{2}{c|}{ Gas discharge, tpy } \\
\cline { 2 - 3 } & \multicolumn{1}{|c|}{ AOF } & Seawater \\
\hline Well 7 & 2.70 & 0.19 \\
\hline Well 8 & 6.73 & 3.37 \\
\hline Well 9 & 5.32 & 3.80 \\
\hline Well 10 (B annulus) & 0.57 & 0.43 \\
\hline Well 10 (C annulus) & 0.36 & 0.09 \\
\hline Well 12 & 0.01 & 0.01 \\
\hline Well 13 & 6.49 & 1.85 \\
\hline Well 14 & 9.80 & 6.30 \\
\hline Well 19 & 1.16 & 0.79 \\
\hline Well 22 & 50.34 & 39.55 \\
\hline Well 25 & 2.86 & 2.04 \\
\hline Well 33 & 0.14 & 0.11 \\
\hline Well 35 & 0.75 & 0.08 \\
\hline Well 36 & 0.19 & 0.11 \\
\hline Well 38 & 0.02 & 0.02 \\
\hline Well 23 (Xu, 2002) & $6.97 \mathrm{E}-07$ & $2.20 \mathrm{E}-04$ \\
\hline Well 24 (Xu, 2002) & $1.55 \mathrm{E}-06$ & $4.40 \mathrm{E}-04$ \\
\hline Case 1 (Huerta, 2009) & 53.92 & 40.44 \\
\hline Case 2 (Huerta, 2009) & 0.02 & 0.02 \\
\hline
\end{tabular}

\subsection{Risk analysis of well integrity failure}

Descriptive statistics of the results is presented in Table 5. It clearly shows mean value of gas discharge either exceeding (AOF) or being slightly smaller (seawater) than the threshold value. However, the mean value of leak rate are much smaller that the threshold value. Moreover, the very small median values of the two well integrity measures indicate that most of the SCP wells studied would pose very small environmental risk.

Significant disparity of the mean and median provides important information about well integrity loss frequency distribution. The histograms in Figure 5 evidence strongly right-skewed distributions with frequent occurrence of small cement leaks resulting 
in small environmental gas discharge. Although only limited to SCP wells that bleed down to zero pressure, the finding is consistent with typical occurrence of various types of leaks (pipelines, flowlines, gathering systems, etc.) where small leaks are more likely than large ones. Moreover, the results also disqualify SCP value as a measure of lost integrity; High values of casing pressure in wells 8 and 9 do not indicate large leaks in these two wells. The observation has been also confirmed with filed data by Bourgoyne et al [6].

Table 5

Descriptive statistics of well integrity measures

\begin{tabular}{|l|l|l|l|l|}
\hline \multirow{2}{*}{ Integrity measure } & \multicolumn{2}{|c|}{ Leak rate, scf/min } & \multicolumn{2}{c|}{ Gas discharge, tpy } \\
\cline { 2 - 5 } & Seawater & \multicolumn{1}{c|}{ Mud } & AOF & Seawater \\
\hline Mean & 5.53 & 4.03 & 7.44 & 5.22 \\
\hline Median & 0.14 & 0.14 & 0.75 & 0.19 \\
\hline Standard deviation & 11.19 & 8.64 & 16.02 & 12.37 \\
\hline Minimum & $9.54 \mathrm{E}-05$ & $6.14 \mathrm{E}-05$ & $6.97 \mathrm{E}-07$ & $2.20 \mathrm{E}-04$ \\
\hline Maximum & 38.86 & 31.66 & 53.92 & 40.44 \\
\hline
\end{tabular}

a)

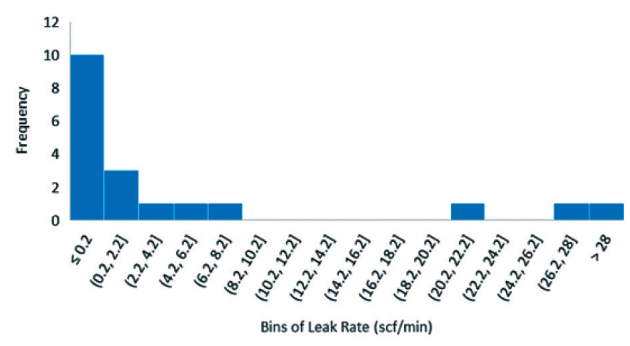

b)

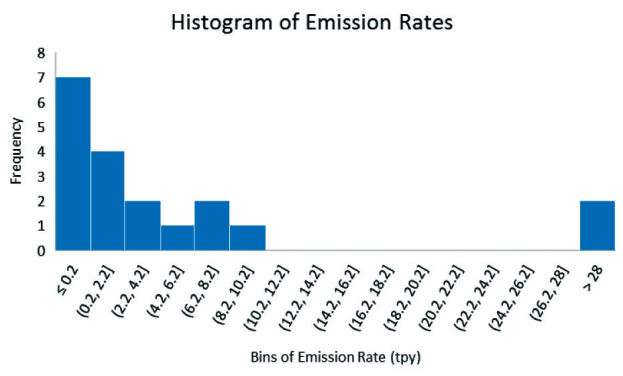

Fig. 5. Strongly right-skewed frequency distribution of integrity loss measures in SCP wells sample:

a) histogram of cement leak rates; b) histogram of environmental gas discharge

Environmental risk of well integrity loss due SCP can be inferred from the plots of cumulative distribution function (CDF) depicted in Figure 6. Figure 6a shows that based on the small (19) sample of SCP wells studied here, there is a 15.8 percent risk of failing the defined threshold for acceptable leak rate, $15 \mathrm{scf} / \mathrm{min}$, using the most conservative assumption of a seawater filled annulus. For the atmospheric (liquid-free) annulus, the risk of failing the environmental gas discharge threshold is 26.3 percent - shown in Figure $6 b$. 
a)

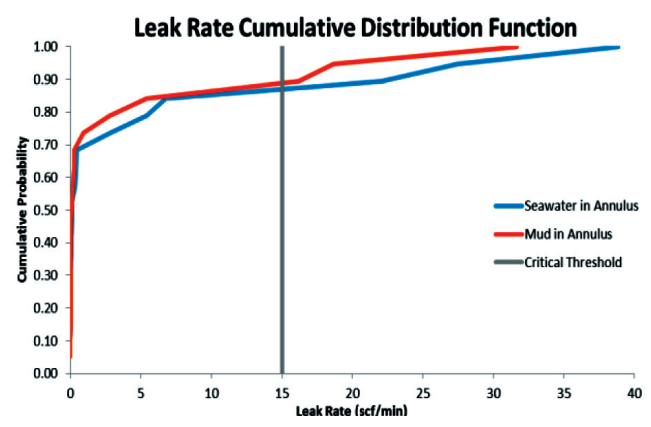

b)

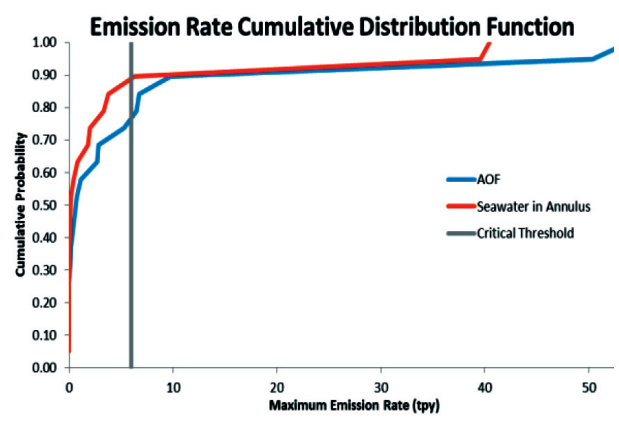

Fig. 6. (CDF) plots for cement leak rate (a), and environmental gas discharge (b)

In all, the study shows that majority of SCP wells that can be bled down to zero pressure during $\mathrm{BB}$ testing, fall below the threshold values for barrier integrity failure and severe environmental discharge risk. However, considering the well sample size and the findings, it could not be concluded with $90 \%$ confidence - a typical standard for statistical measures - that a SCP well that bleeds down to zero pressure would meet the two proposed criteria of low environmental risk. Thus, the practice of the sole reliance on pressure bleed-down for the determination of an acceptably low risk is not corroborated with the findings of this work.

For present industry practices, and using the two measures of integrity failure proposed in this work, there is merely 84 percent and 74 percent probability the SCP well displays small cement leak and pose no risk of serious gas discharge, respectively.

More general observations can be also made from the plots in Figure 6 concerning different scenarios (on-shore, and off-shore) of the annular fluid variants considered (seawater or mud). The data shows that disregarding the well's location (on-shore/ off-shore) 70 percent of SCP wells would have undetected size of cement leak. However, these extremely small leaks would still generate unacceptable environmental gas discharge since the probability of undetected gas discharge (Fig. 6b) is much smaller $-40 \%$, and $50 \%$ for no-liquid (AOF), seawater variants, respectively.

\subsection{Statistical analysis of $24-\mathrm{hr}$ pressure buildup criterion relevance}

As discussed above, 24-hour pressure buildup is another indicator of integrity loss problem severity. It is, therefore, reasonable to examine viability of this predictor by testing a possible correlation between the 24-he pressure build-up and the two other measures of well integrity. As shown in Figure 7, the plots of gas discharge and cement leak rate vs. 24-hr pressure buildup yield no apparent correlation. The attempt to fit 
several curves would yield generally poor fits. It suggests that pressure buildup rate is also controlled by a factor other than the rate of gas in the cement but, most likely, strongly depends on gas migration in the liquid column above the cement top. Consequently, pressure buildup rate might not be a reliable indicator of the cement barrier integrity loss.

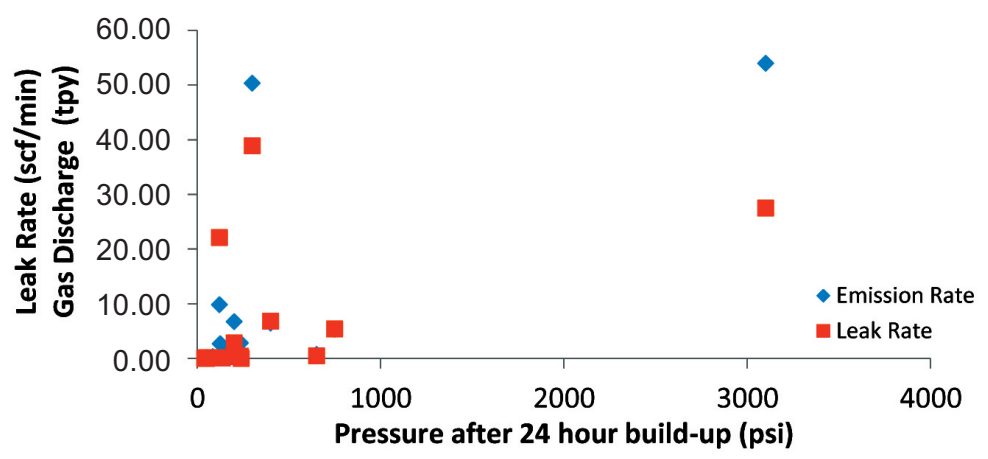

Fig. 7. Lack of correlation between 24-hr pressure buildup and other measures of well integrity

\section{CONCLUSION}

Regulatory metrics (10 CFR 250 Subpart E) of sustained casing pressure (SCP) and industrial practice [4] are mostly qualitative and not specific about analyzing the risk of the SCP problem. They state that SCP wells with annular pressures that can be bled-down to zero followed with 24-hour pressure buildup lower than the initial pressure represent 'an acceptable risk' and concludes that the leak rate is sufficiently low and that a barrier is sufficiently intact. The two risk criteria are examined in this study leading to the following conclusions:

1. Two new quantitative well integrity metrics are proposed with their threshold values defining acceptable level of integrity loss: $15 \mathrm{scf} / \mathrm{min}$ gas flow rate across the leaking cement, and 6 ton per year (tpy) well gas discharge to the environment.

2. Field data from a SCP testing of 19 wells - all having casing pressure bled down to zero - are analyzed using customized software to determine the values of the proposed new metrics

3. It was determined that three of the 19 wells $(15.8 \%)$ would fail the cement barrier threshold, in the two scenarios tested-one in which the weighted drilling fluid remained in the annulus and the other which assumed that fluid would be replaced with a seawater of density $8.6 \mathrm{ppg}$. 
4. It was determined that $15.8 \%$ and $26.3 \%$ of SCP wells would exceed the acceptable amount of gas discharge from well to environment for offshore location and onshore locations, respectively

5. The results show that majority of SCP wells that can be bled down to zero pressure during SCP testing, fall below the threshold values for barrier integrity failure and below the limit of severe environmental discharge risk. However, considering the well sample size and the findings, it could not be concluded with $90 \%$ confidence that a SCP well that bleeds down to zero pressure would meet the two proposed criteria of low environmental risk. Therefore, the practice of the sole reliance on pressure bleed-down for the determination of an acceptably low risk is not corroborated with the findings of this work.

6. For present industry practices, and using the two measures of integrity failure proposed in this work, there is merely 84 percent and 74 percent probability the SCP well displays small cement leak and pose no risk of serious gas discharge, respectively.

7. The 24-hour pressure buildup is examined as another currently-used indicator of well integrity loss severity by testing its correlation with two other integrity metrics. No correlation is found as pressure buildup is possibly controlled by other factors. Consequently, pressure buildup rate might not be a reliable indicator of the cement barrier integrity loss.

\section{Nomenclature}

$$
\begin{gathered}
P_{i}-\text { initial wellhead pressure, psi } \\
T_{b d}-\text { pressure bleed-down time, hours } \\
P_{24 \mathrm{hr}}-\text { 24-hour pressure build-up, psi } \\
I D-\text { nominal casing inner diameter, inches } \\
O D-\text { nominal casing outer diameter, inches } \\
\rho_{m}-\text { mud density in annulus, lb/gal } \\
L_{c}-\text { length of the cement column, feet } \\
L_{f}-\text { length of the fluid column, feet } \\
k-\text { cement permeability, mD } \\
p_{f}-\text { gas formation pressure, psi }
\end{gathered}
$$




\section{REFERENCES}

[1] 30 CFR Part 250.519-531: Casing Pressure Management U.S. Code of Federal Regulations.

[2] 40 CFR Subchapter C Part 60 Subpart OOOO: Standards of Performance for New Stationary Sources. U.S. Code of Federal Regulations.

[3] Al-Tamini A., Al-Mansoori S., Samad S., Al-Shagga M., Hussain A., Ghneim G.J., Sakkaf A.: Design and Fabrication of a Low Rate Metering Skid to Measure Internal Leak Rates of Pressurized Annuli for Determing Well Integrity Status. 2008 Abu Dhabi International Petroleum Exhibition and Conference, Abu Dhabi, United Arab Emirates, 3-6 November 2008, SPE-117961-MS.

[4] API Recommended Practice 90: Annular Casing Pressure Management for Offshore Wells. API Publishing Services, Washington, D.C., 2006.

[5] API Recommended Practice 14J: Recommended Practice for Design and Hazards Analysis for Offshore Production Facilities. API Publishing Services, Washington, D.C., 2013.

[6] Bourgoyne A., Scott S., Manowski W.: A Review of Sustained Casing Pressure Occurring on the OCS. Minerals Management Service, Washington, D.C., 2000.

[7] Bourgoyne A.T., Millheim K.K., Chenevert M.E., Young F.S.: Applied Drilling Engineering. 1st ed. Society of Petroleum Engineers, Richardson, TX, 1986.

[8] Huerta N.J, Checkai D., Bryant S.L.: 2009. Utilizing Sustained Casing Pressure Analog to Provide Parameters to Study $\mathrm{CO}_{2}$ Leakage Rates Along a Wellbore. SPE International Conference on $\mathrm{CO}_{2}$ Capture, Storage, and Utilization, San Diego, California, USA, 2-4 November 2009, SPE-126700-MS.

[9] Josey R., Hoshman R., Patton, F.: Investigation of Blowout Main Pass Block 91 OCS-G 14576. Minerals Management Service Gulf of Mexico OCS Regional Office, New Orleans, LA, 2008. (August 23, 2007).

[10] Kazemi M., Wojtanowicz A.K.: Development of Improved Testing Procedure for Wells with Sustained Casing Pressure. SPE Annual Technical Conference and Exhibition, Amsterdam, The Netherlands, 27-29 October 2014, SPE-170693-MS.

[11] Kinik K., Wojtanowicz A.K.: Identifying Environmental Risk of Sustained Casing Pressure. SPE Americas E\&P Health, Safety, Security, and Environment Conference, Houston, TX, USA, 21-23 March 2011, SPE-143713-MS.

[12] OLF 117 Norwegian Oil and Gas Recommended Guidelines for Well Integrity. Norwegian Oil and Gas Association, Stavanger, Norway 2011. 
[13] Rocha-Valadez T., Hasan A.R, Mannan S., Kabir C.S.: Assessing Wellbore Integrity in Sustained-Casing-Pressure Annulus. SPE-169814-PA, 2014.

[14] Weaver J.L.: Offshore Safety in the Wake of the Macondo Disaster: The Role of the Regulator. Houston Journal of International Law, 36 (379), 2014, pp. 124.

[15] Xu R., Wojtanowicz A.K.: Diagnosis of Sustained Casing Pressure from Bleed-off/ Buildup Testing Patterns. SPE Production and Operations Symposium, Oklahoma City, Oklahoma, 24-27 March 2001, SPE-67194-MS.

[16] Zhu H., Lin Y., Zeng D., Deping Z., Feng W.: Calculation analysis of sustained casing pressure in gas wells. Petroleum Science, 9 (1), 2012, pp. 66-74. 